\title{
Does flood rhythm drive ecosystem responses in tropical riverscapes?
}

\author{
Timothy D. Jardine, $, 2,3,10$ Nicholas R. Bond, ${ }^{2}$ Michele A. Burford, ${ }^{2}$ Mark J. Kennard, ${ }^{1,2}$ Douglas P. Ward, ${ }^{1,2}$ \\ Peter Bayliss, ${ }^{1,4}$ Peter M. Davies, ${ }^{1,5}$ Michael M. Douglas, ${ }^{1,6}$ Stephen K. Hamilton, ${ }^{7}$ John M. Melack, ${ }^{8}$ \\ Robert J. Naiman, ${ }^{5,9}$ Neil E. Pettit, ${ }^{1,5}$ Bradley J. Pusey, ${ }^{1,5}$ Danielle M. Warfe, ${ }^{5}$ and Stuart E. Bunn ${ }^{1,2}$ \\ ${ }^{1}$ National Environmental Research Program, Northern Australia Hub, Department of the Environment, GPO Box 787, Canberra, \\ Australian Capital Territory 2601 Australia \\ ${ }^{2}$ Australian Rivers Institute, Griffith University, Nathan, Queensland 4111 Australia \\ ${ }^{3}$ School of Environment and Sustainability, Global Institute for Water Security, University of Saskatchewan, Saskatoon, \\ Saskatchewan S7H4J6 Canada \\ ${ }^{4}$ CSIRO, Ecosciences Precinct, Brisbane, Queensland 4102 Australia \\ ${ }^{5}$ Center of Excellence in Natural Resource Management, University of Western Australia, Albany, Western Australia 6332 Australia \\ ${ }^{6}$ Charles Darwin University, Darwin, Northern Territory 0909 Australia \\ ${ }^{7}$ Kellogg Biological Station, Michigan State University, Hickory Corners, Michigan 49060 USA \\ ${ }^{8}$ University of California, Santa Barbara, California 93106 USA \\ ${ }^{9}$ University of Washington, Seattle, Washington 98195 USA
}

\begin{abstract}
Biotic communities are shaped by adaptations from generations of exposure to selective pressures by recurrent and often infrequent events. In large rivers, floods can act as significant agents of change, causing considerable physical and biotic disturbance while often enhancing productivity and diversity. We show that the relative balance between these seemingly divergent outcomes can be explained by the rhythmicity, or predictability of the timing and magnitude, of flood events. By analyzing biological data for large rivers that span a gradient of rhythmicity in the Neotropics and tropical Australia, we find that systems with rhythmic annual floods have higher fish species richness, more stable avian populations, and elevated rates of riparian forest production compared with those with arrhythmic flood pulses. Intensification of the hydrological cycle driven by climate change, coupled with reductions in runoff due to water extractions for human use and altered discharge from impoundments, is expected to alter the hydrologic rhythmicity of floodplain rivers with significant consequences for both biodiversity and productivity.
\end{abstract}

Key words: arrhythmic systems; Australia; biodiversity; flood pulse; floodplain; hydrologic cycle; Neotropics; productivity; rhythmicity; river basins; stochasticity.

\section{INTRODUCTION}

Many plant and animal phenologies and communityscale processes are aligned with annual cycles in abiotic factors, such as temperature and day length (Foster and Kreitzman 2009, Helm et al. 2013). The predictable recurrence of annual events exerts strong selective pressures on individual species, resulting in adaptations to maximize fitness. Such systems may be described by deterministic models that consider how certain traits of a particular species allow it to thrive under the existing set of environmental conditions, i.e., the niche (Clark 2008). If events are, instead, stochastic or unpredictable, selection will favor a different set of behavioral, lifehistory, and morphological adaptations and species assemblages that may be better described by neutral models (Rosindell et al. 2012). Understanding the

Manuscript received 24 May 2014; revised 7 July 2014; accepted 27 August 2014. Corresponding Editor: K. O. Winemiller.

${ }^{10}$ E-mail: tim.jardine@usask.ca relative influence of deterministic and stochastic forces in shaping biological communities has long challenged ecologists (Gravel et al. 2011).

River biotas are strongly influenced by flow regimes (Lytle and Poff 2004), which show considerable variation in predictability among rivers worldwide (Puckridge et al. 1998). Discharge patterns, including flood events, have often been severely modified by dams and diversions (Poff et al. 2007), and additional changes are predicted under climate change scenarios (Döll and Zhang 2010). Because the collective adaptations of species assemblages interact with environmental conditions to determine ecosystem structure and function (Lewis et al. 2000), other features of fluvial ecosystems will be influenced by changes in the predictability of flows (Sabo et al. 2010). Synthetic comparative efforts are needed to link the hydrologic properties of large floodplain rivers with biotic assemblages and their functions, including the provision of food and fiber for human societies (Tockner and Stanford 2002).

Ecosystem services derived from floodplains arise from the flood-pulse advantage, an enhancement of 
biological production in response to flooding (Junk et al. 1989). However, there is growing recognition that not all floods are equal, and differences in the magnitude and predictability of floods shape biological responses (Lytle and Poff 2004). While seasonally predictable floods are important drivers of floodplain productivity in many systems (Winemiller 2004), elsewhere, large, infrequent, and unpredictable floods act as a major form of disturbance, capable of substantially moderating basinscale productivity (Parsons et al. 2005). Thus, there is a tension between the replenishing and damaging forces that arise from floods of differing magnitude and predictability (Lake et al. 2006). Despite recognition of this variability, there is no framework to evaluate patterns in productivity and biodiversity and how rivers and their floodplains may respond to human-induced alterations to flow, particularly at the basin scale (Palmer et al. 2008).

Here, we quantify effects of flood regimes across structural and/or functional and aquatic and/or terrestrial dimensions to elucidate how hydrology controls the ecology of floods in large tropical rivers. We, first, evaluate the range of variation in river-floodplain rhythmicity across a gradient of large river basins from tropical latitudes, and then examine a set of ecological and biogeochemical properties associated with those rivers. Earlier approaches to conceptualize river ecosystems have been hampered by the lens through which biological features are viewed. As noted previously (Marcarelli et al. 2011), most studies have related abiotic drivers to either structural (e.g., patterns such as species diversity and food web linkages) or functional characteristics (e.g., processes such as biomass production and gas exchanges) separately rather than simultaneously relating abiotic drivers to multiple biotic properties. Further, the spatially complex and interconnected nature of river landscapes (hereafter, riverscapes, encompassing drainage channel networks, riparian zones, and floodplains) means that a purely terrestrial or aquatic focus is inadequate.

\section{Methods}

We used hydrometric data to characterize the rhythmicity of flood regimes in a set of large river basins. Because biodiversity is known to peak at low latitudes (Willig et al. 2003), we chose rivers that had some portion or all of their catchment located in the tropics to minimize the effects of latitude on ecosystem pattern and process. We accessed long-term daily discharge records from the Global Runoff Data Centre (GRDC; available online), ${ }^{11}$ and limited our analyses to gauges with more than 20 years of data. We focused our efforts on gauges located in South America, Mexico, and northern Australia, where river regulation by dams and human-altered land cover are comparatively low,

\footnotetext{
$11 \mathrm{http}: / /$ www.bafg.de/GRDC/EN/Home/homepage_ node.html
}

and the confounding influence of recent glaciation is absent. From these, we selected those with upstream contributing areas greater than $10000 \mathrm{~km}^{2}$ (90 gauges in total; Appendix A: Fig. A1), thus ensuring that the basin contained a significant floodplain (by surface area; Tockner and Stanford 2002).

The area of floodplain subject to seasonal inundation is well correlated with river stage and discharge (Appendix B: Fig. B1); therefore, we used daily discharge data from in-channel gauges to calculate summary metrics of the flood regime. Given the redundancy in many flow metrics, we selected two that describe the hydrologic rhythmicity of large river floodplains, the coefficient of variation (percentage) of the maximum annual flood peak $\left(\mathrm{CV}_{\max }\right)$ to describe variation in flood magnitude; and the circular variance, a measure of the spread associated with a circular mean (the day of year of the maximum annual flood peak; $\mathrm{PRED}_{\text {time }}$ ) to describe variation in flood timing. A perfectly rhythmic floodplain would receive a flood peak of identical magnitude $\left(\mathrm{CV}_{\max }=0\right)$ on exactly the same day every year $\left(\mathrm{PRED}_{\text {time }}=0\right)$, whereas a perfectly arrhythmic floodplain effectively exhibits random flooding, with a flood of any given size possible at any time of year.

Our selected river basins likely cover most of the global range in rhythmicity because Australian dryland rivers are known to be among the most temporally variable in the world (Puckridge et al. 1998), and large Amazonian tributaries have relatively low interannual variation in flood timing and magnitude. We ranked the $\mathrm{CV}_{\max }$ and $\mathrm{PRED}_{\text {time }}$ of the 90 discharge gauges and used average rank (rhythm rank score) as an overall indicator of rhythmicity, with scores close to one indicating rhythmicity and scores close to 90 indicating arrhythmicity. Our measure of interannual variation in flood magnitude $\left(\mathrm{CV}_{\max }\right)$ was correlated $(r=0.57)$ with a seasonality index (percentage contribution of the six driest months of the year to total annual discharge; Appendix C: Fig. C1), and, thus, it incorporates elements of both the low and high flow regime (Sabo and Post 2008).

We compared our rhythm rank scores with a set of biological features of tropical riverscapes that should be influenced by hydrologic rhythmicity and for which data were available. These included primary productivity of floodplain forests (terrestrial process), export of dissolved organic carbon (DOC; aquatic process), avian species richness and population variability (terrestrial pattern) and fish species richness (aquatic pattern).

We used rates of riparian forest production to indicate how river rhythmicity influences ecosystem processes in terrestrial areas. We estimated net primary productivity (NPP) of floodplain forests using modeled values from a global database (Kucharik et al. 2000). We used a valley bottom flatness index (Gallant and Dowling 2003) combined with images of remotely sensed inundation (Melack and Hess 2010) to obtain an objective estimate 
of floodplain area (independent of vegetation) and extracted NPP for delineated floodplains from an online database (Kucharik et al. 2000). Though we were unable to validate this approach with on-ground data for the Australian basins, we compared the model-derived estimate with on-ground measurements made in the central Amazon (Junk 1997) and found good agreement (model estimate $\sim 913 \mathrm{Mg} \mathrm{C} \cdot \mathrm{km}^{-2} \cdot \mathrm{yr}^{-1}$; on-ground estimate 800 to $1250 \mathrm{Mg} \mathrm{C} \cdot \mathrm{km}^{-2} \cdot \mathrm{yr}^{-1}$; Junk 1997).

Basin-scale data for aquatic ecosystem processes are scarce. One measure, catchment export of dissolved organic carbon (DOC), was available for six South American basins (collated in Aitkenhead and McDowell 2000 ) and two Australian basins (Daly River, Robson et al. 2010; Cooper Creek, S. Hamilton, unpublished data). Data for the South American basins and the Daly River are calculated based on measurements made across a range of flow conditions, while the Cooper Creek data are estimated from samples collected during low flows only. We used this as an approximate indicator of controls by rhythmicity on aquatic carbon flux.

To index response of riparian terrestrial biota to flood rhythmicity, data were compiled from a database of bird species observations from Australian basins maintained by BirdLife Australia. ${ }^{12}$ We calculated species richness in each basin as well as two standard measures of population variability, the standard deviation of $\log$ counts, and the $\mathrm{CV}$ of abundance, for a subset of species with available data (present in $n \geq 8$ basins) that potentially respond to flood regimes because they depend on water or riparian corridors for feeding, nesting, and refuge. These latter values incorporated both temporal and spatial variability in abundance within catchments, and, thus, can be considered measures of the repeated expansion and contraction of populations.

Our aquatic pattern indicator was fish species richness, because fish play important and varied trophic roles in tropical rivers. We used data presented in Pusey et al. (2011) for northern Australian basins and in Albert et al. (2011) for South American basins. Data presented in Pusey et al. (2011) were based on museum records, published survey accounts, and unpublished survey data (B. Pusey, M. Kennard, and D. Burrows, unpublished data) for almost 7000 sites throughout northern Australia. These data form a significant component of the most recent assessment of the conservation value of aquatic ecosystems of the region (Kennard et al. 2010). Recognizing the limitations in accurately assessing species diversity for South America, a large and incompletely inventoried region (Alofs et al. 2014), we used fish river basin species richness from Albert et al. (2011), which currently provides the most comprehensive assessment based on $\sim 5600$ Neotropical species.

\footnotetext{
$12 \mathrm{http}: / /$ birdlife.org.au/projects/atlas-and-birdata
}

For all analyses, we log-transformed response data, where appropriate, and used simple linear or exponential regressions to test for relationships between rhythmrank scores and biological characteristics using SPSS (SPSS, Chicago, Illinois, USA). Because larger basins are known to contain more diverse assemblages (Guégan et al. 1998), we scaled all fish diversity measures to basin size by dividing by catchment area. Similarly, we report both floodplain NPP and DOC export on a per-unit-area basis, thus removing the potential confounding effect of river size.

\section{Results}

Our rhythm framework shows that there are large differences within and among the two study regions in the predictability of the magnitude and timing of floods (Fig. 1). Between regions, differences are most pronounced for interannual variation in flood magnitude $\left(\mathrm{CV}_{\max }\right)$, whereas predictability of flood timing $\left(\mathrm{PRED}_{\text {time }}\right)$ is more comparable between the two regions (Fig. 1A). Floods in Australian rivers are generally less rhythmic than those in South American and Mexican systems (Fig. 1B). Australian rivers rank between 64th (Daly River) and 90th (Cooper Creek) out of the 90 basins in $\mathrm{CV}_{\max }$ (ranging from 61 to 197\%), and South American and Mexican rivers had $\mathrm{CV}_{\max }$ ranging from 4 to $131 \%$ and ranking from 1st (Rio Purus) to 87 th (Rio Bana Buiú). Temporal variation in Australian rivers reflects the climatic range from the more predictable monsoonal tropics (e.g., Daly River, PRED $_{\text {time }}=0.08$, ranked 14) to less predictable dryland rivers draining the continent's interior (e.g., Cooper Creek, PRED time $=$ 0.55, ranked 80). South American rivers varied in PRED $_{\text {time }}$ from 0.02 in the Orinoco River (ranked 1) to 0.93 in the Rio Ivaí (ranked 90), the latter lacking a distinct rainy season that leads to floods throughout the year (Fig. 1C).

Analysis of structural and functional features of aquatic and terrestrial riverscape components revealed that ecological responses to flood rhythmicity vary in direction, form, and strength. For example, variation in floodplain forest annual NPP is negatively related to rhythm rank score for the Australian river basins $\left(r^{2}=\right.$ $0.42, P=0.007$, Fig. 2A). The analysis also suggests possible links between rhythmicity and export of dissolved organic carbon (DOC) across all rivers $\left(r^{2}=\right.$ $0.54, P=0.037$, Fig. 2B). Australian bird species richness is related to rhythmicity $\left(r^{2}=0.35, P=0.043\right.$; data not shown), and when examined for particular functional and taxonomic groups, correlations between rhythm rank score and measures of population variation (SD of $\log$ counts and CV) were almost uniformly positive (Fig. 2C), suggesting that less rhythmic rivers have more variable avian populations. A significant amount of variation in fish species richness was explained by the flood rhythm of the Australian basins $\left(r^{2}=0.54, P=\right.$ $0.006)$ and for the two regions combined $\left(r^{2}=0.43, P=\right.$ 

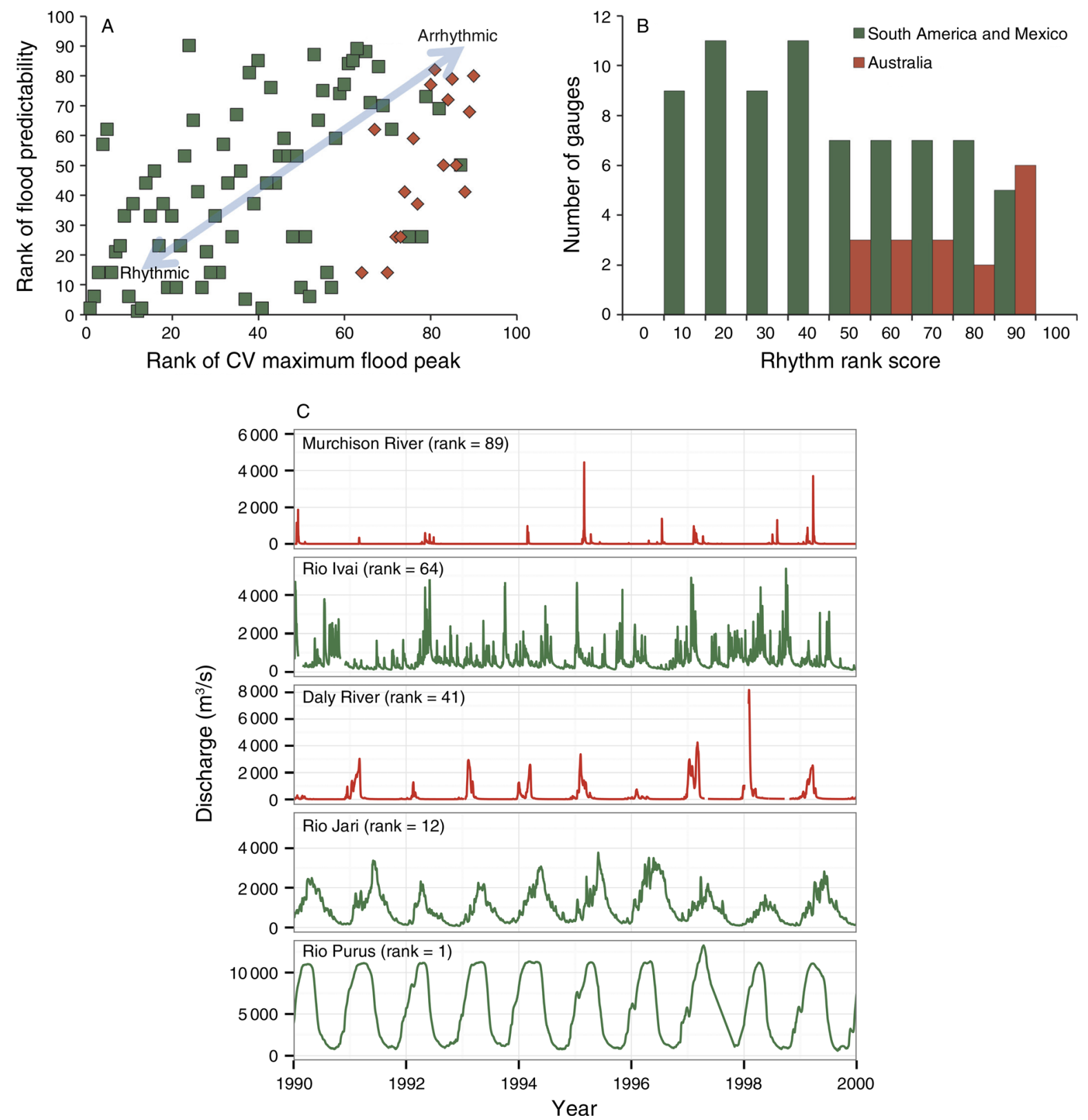

FIG. 1. The rhythmicity of river floodplains in South America and Mexico (green squares) and Australia (orange diamonds), as indicated by summary metrics of the long-term flood regime. (A) A gradient of rhythmicity (indicated by the arrow) distinguishes floodplains ranked on the basis of predictability in timing ( $\mathrm{PRED}_{\text {time, }} y$-axis) and interannual variation in the maximum flood peak $\left(\mathrm{CV}_{\max }, x\right.$-axis), (B) frequency histogram of rhythm rank scores (average of CVmax and PREDtime) for the two main regions, and (C) examples of monthly discharge hydrographs of representative floodplains. The five example rivers, from top to bottom, are from western Australia, southern Brazil, north-central Australia, and the eastern and western Amazon in Brazil.

0.001), but not for the South American basins alone $\left(r^{2}\right.$ $=0.01, P=0.795$; Fig. 2D).

\section{Discussion}

These results reveal the broad range of hydrological rhythms and ecological responses in floodplain riverscapes of two tropical regions. Fish and bird species assemblages and two important ecosystem processes respond to this gradient. Fish species richness is higher, avian populations are more stable, and forests are more productive when river flow is more rhythmic. Aquatic primary and secondary production is stimulated when seasonal warm temperatures and sustained flood pulses are synchronized (Winemiller 2004). In contrast to the wet tropics, where river flow pulses tend to be rhythmic, rivers in semiarid to arid climates generally have arrhythmic discharge (Fig. A1) associated with low mean annual runoff (Appendix C: Fig. C2). Despite 

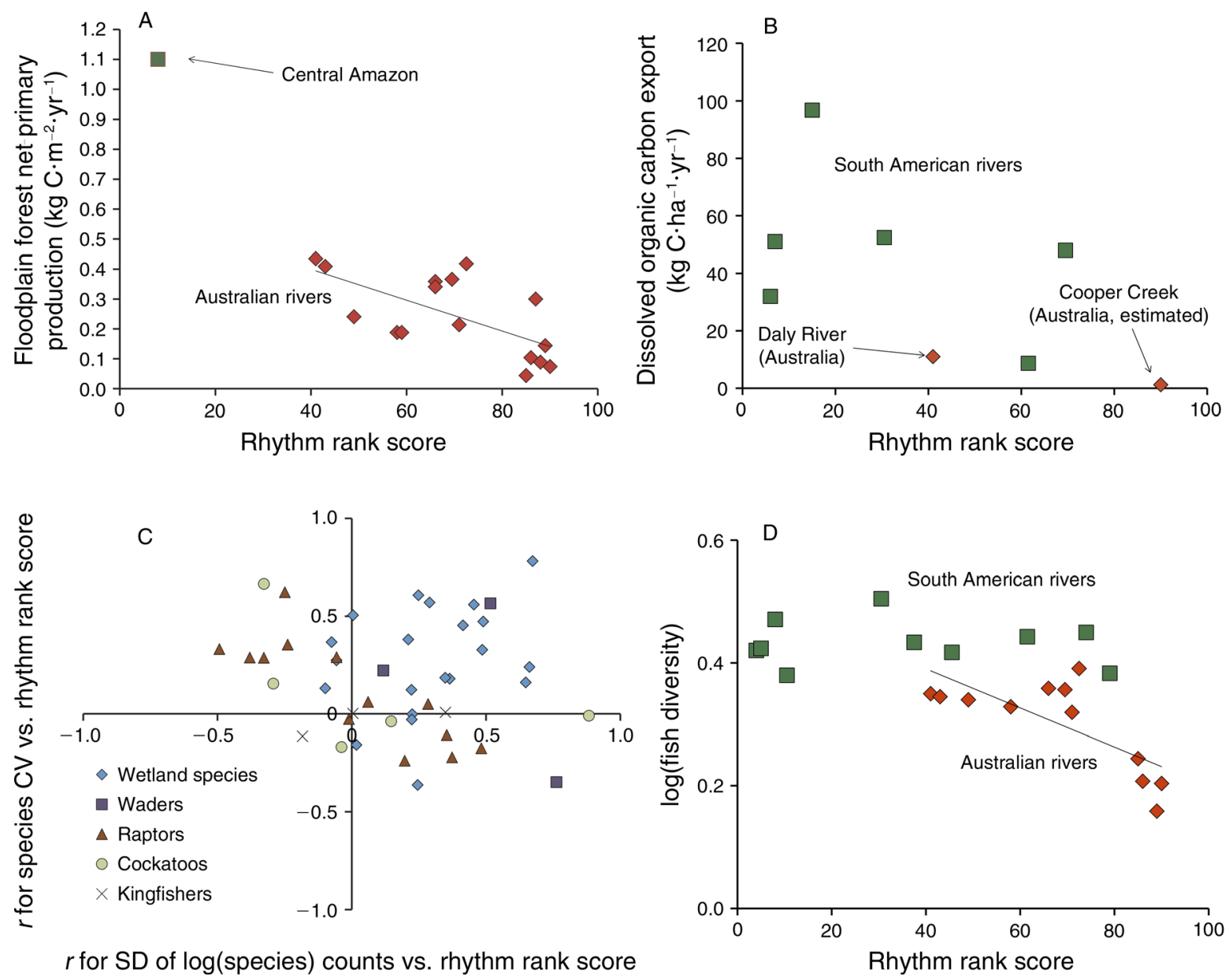

$r$ for SD of log(species) counts vs. rhythm rank score

FIG. 2. Relationship between hydrological rhythms of tropical rivers (rhythm rank score) and (A) riparian forest production, (B) dissolved organic carbon export, (C) avian population variability, and (D) fish species diversity (diversity is log[species]/ $\log [$ catchment area]). Rhythm rank score is the average rank from Fig. 1. In panel (C), correlation coefficients $(r)$ denote speciesspecific responses in population CV ( $y$-axis) and the logarithm of species counts ( $x$-axis) to rhythm rank score (i.e., a positive $r$ implies greater population variability associated with a higher rhythm rank score).

having daily flood peaks that rival and often exceed those of rhythmic rivers (Appendix C: Fig. C2), arrhythmic rivers have floodplains dominated by sparse catchment vegetation (Fig. 3A) and limited export of DOC (Fig. 3B). Birds in arrhythmic rivers show variable population abundances (Fig. 3C) with boom and bust cycles that likely reflect their well-known ability to disperse and track surface water availability (Kingsford and Norman 2002). Such arrhythmic rivers support opportunistic fish species that are tolerant to high temperatures, low oxygen, and high turbidity that are often associated with no-flow conditions (Sabo et al. 2010). More rhythmic rivers support a greater number of species that require access to permanent floodplain wetland habitats (Fig. 3D, Lewis et al. 2000) and provide a greater flood pulse advantage for aquatic consumers. This latter feature is frequently revealed by a disconnect between the stable isotopic signatures of fish and local food resources in channel habitats of rivers that experience extensive and relatively predictable flood pulses (Fig. D1). Many other ecological processes, such as secondary productivity and nutrient release rates from sediments and soils (Bechtold et al. 2003), as well as important interactions among producers, grazers, and predators (Power et al. 2008), are affected by hydrologic rhythmicity.

In theory, harsh and fluctuating environments limit diversity in biological communities. The relative abundances of two competing species are determined by differences in their ratios ( $E: b)$, wherein $E$ is the average environmental response and $b$ is sensitivity to competition (Chesson and Huntly 1997). Under a scenario of regular but predictable disturbance (e.g., high flood rhythmicity), extinction probabilities do not increase because disturbance averages out over time and competitively inferior species exhibit positive growth rates at low densities, an important criterion for stable coexistence (Gravel et al. 2011). Further, predictable 


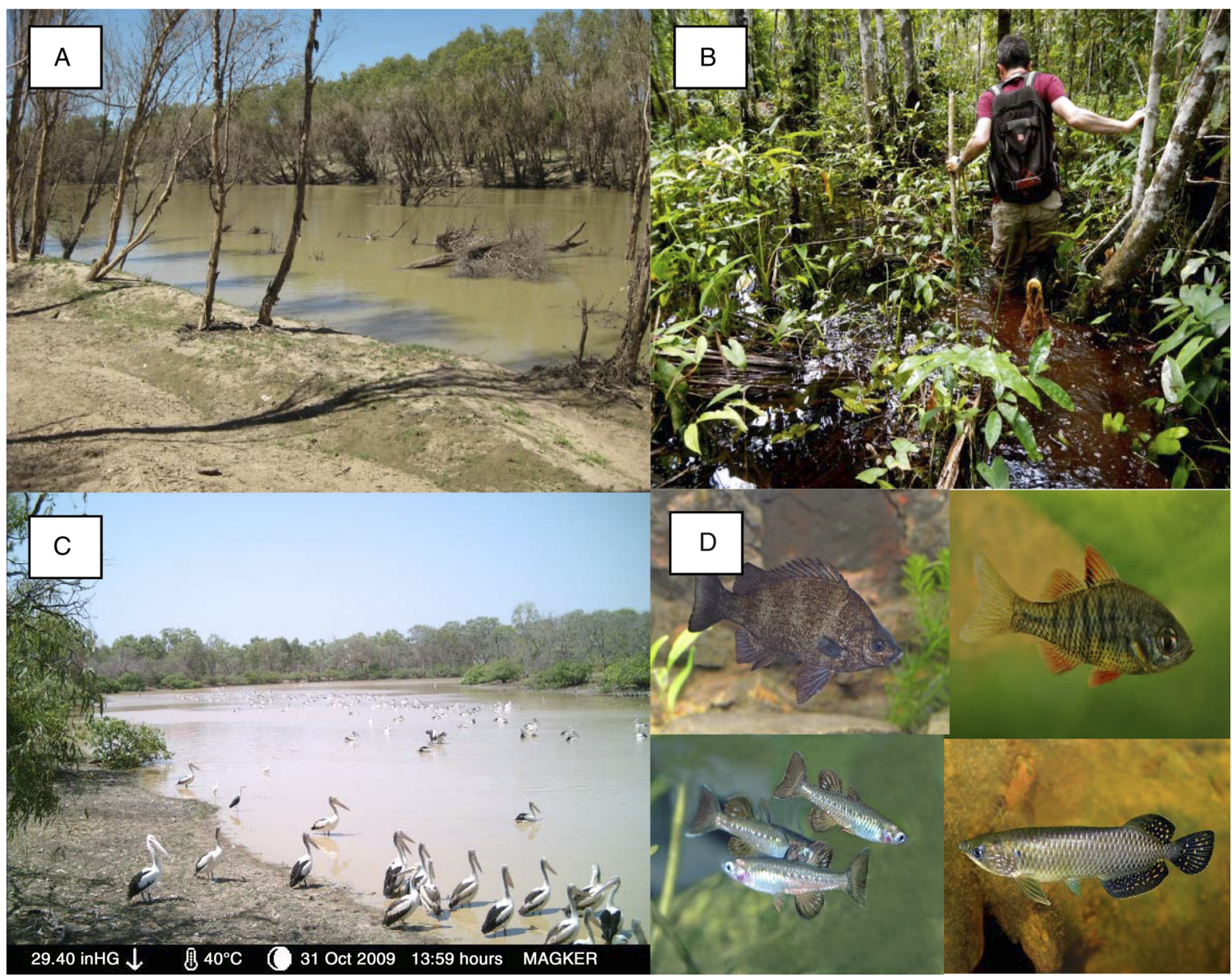

FIG. 3. (A) Defoliated and damaged vegetation along the arrhythmic Flinders River, Australia after recession of an extended flood in the Austral summer of 2009. Floods of similar duration that occur annually in the Amazon lead to high productivity because of local adaptations of tree species to submergence and anoxia. Photo credit: Stephen Hamilton. (B) The floodplain of the Napo River, an Amazonian tributary in Ecuador, often has waters rich in dissolved organic carbon. Photo credit: Kateryna Rybachuk. (C) Pelicans in a floodplain waterhole of the Mitchell River, Australia. Highly variable avian populations occur commonly in arrhythmic rivers. Photo credit: Tim Jardine. (D) Some of the fish species that are common in the most rhythmic Australian rivers (clockwise from top left: lake grunter Variiichthys lacustris, pennyfish Denariusa bandata, saratoga Scleropages jardinii, delicate blue eye Pseudomugil tenellus (images by Neil Armstrong).

disturbances, such as rhythmic floods, would allow a larger suite of organisms to maintain viable populations via storage effects, or to persist during unfavorable conditions (Chesson et al. 2004). Hence, though rhythmic rivers could be described as harsh, fluctuating environments, their relatively predictable fluctuations may promote more diverse and productive communities (Chesson and Huntly 1997). Under stochastic disturbance or non-stationarity (e.g., a new flow regime introduced by a dam), local extinctions are, instead, hastened by competitive exclusion or random drift (Chesson and Huntly 1997). Many arrhythmic rivers experience occasional periods of drought and no flow which represents a second type of disturbance. Harsh drought conditions reduce critical resources and populations of aquatic organisms, but are eventually followed by rapid population growth when flows are reestablished
(Burford et al. 2008) and a return to intense competition until the next disturbance event.

Differences in diversity between rhythmic and arrhythmic rivers are consistent with the intermediate disturbance hypothesis (IDH) that predicts peaks in species diversity at intermediate levels of disturbance. Since the development of the IDH, a variety of diversity vs. disturbance relationships have been observed (Mackey and Currie 2001) that likely arise from difficulties in characterizing and measuring disturbance (Shea et al. 2004). Though aspects of disturbance normally considered include frequency, extent, intensity, and duration, only recently has clarity emerged around the simultaneous characterization of disturbance in multiple dimensions (Miller et al. 2011). While variation is implicit in all of these aspects, predictability of the disturbance may be as important as its magnitude. 
Our rhythm framework characterizes disturbance as regular and predictable vs. irregular and unpredictable, and our two-dimensional rhythm rank scores can be examined as sample distributions for each component variable (Fig. 1 and Appendix E; cf. Miller et al. 2011). These event distributions show a more normal distribution of intensity and frequency for highly rhythmic systems and a dispersed, right-skewed distribution for frequency and intensity for highly arrhythmic systems. Thus, within a given arrhythmic system, the interval between floods is always too long and flood size is too small, favoring few strong competitors, or the interval is too short and flood size is too large, favoring few tolerant species. More rhythmic systems, conversely, are subject to disturbance that is intermediate in both frequency and intensity. Arrhythmicity also increases the likelihood that a flood pulse will occur during cooler months with a reduced photoperiod, and thus outside the optimal period for growth. These aseasonal flood pulses are likely to limit, rather than enhance, diversity and production (Winemiller 2004), much like the arrhythmic rivers shown here.

If our reasoning is correct, then neutral models of species diversity (e.g., Muneepeerakul et al. 2008) should predict better for regions with less rhythmic rivers, because rates of birth, death, and immigration in response to the disturbance regime, rather than local niche partitioning, will most strongly influence assemblage structure. Given that predictability, as a measure of disturbance, has long been debated (e.g., Poff 1992), there is little doubt that seasonally predictable environments provide greater opportunities for specialized lifehistory adaptations than do unpredictable environments. This entails a necessary trade-off in the relative fitness benefits of particular life histories across gradients of predictability. The generalist diets and habitatuse patterns of fishes in arrhythmic Australian rivers (Pusey et al. 2011) support this assertion, whereas the highly diverse and ecologically specialized fishes of rhythmic South American basins (Lewis et al. 2000, Correia and Winemiller 2014) suggest that deterministic models would better explain patterns of local species richness. Until more species distribution data become available for South American systems (Albert et al. 2011, Alofs et al. 2014) to allow testing of neutral models, this remains speculative. Higher fish diversity for a given rhythm rank score for South American basins compared to Australian basins (Fig. 1D) is likely a function of the former's greater regional species pool within a greater land area, and the latter's paleohistory of desertification that caused many species extinctions (Unmack 2001).

Latitude and local geomorphology also may have influenced ecological patterns and processes within and across the two regions. By constraining our analysis to tropical basins, our gauges covered a latitudinal range of 52 degrees $\left(29^{\circ} \mathrm{S}\right.$ to $\left.22^{\circ} \mathrm{N}\right)$. The Australian gauges, those having the strongest rhythmicity-diversity relationships, spanned a lesser latitudinal gradient $\left(27^{\circ} \mathrm{S}\right.$ to $\left.14^{\circ} \mathrm{S}\right)$. Diversity of many higher taxa peaks at these tropical latitudes, and significant diversity-latitude relationships are uncommon across such a narrow range (Willig et al. 2003). Expansion of our framework to include other regions should consider latitude as a potential covariable. Channel and floodplain geomorphology also strongly influence patterns of nutrient retention and transformation (Noe et al. 2013); thus, biological diversity and productivity in both rhythmic and arrhythmic rivers are likely modulated by the landforms through which they flow (hydrogeomorphic patches sensu Thorp et al. 2008).

Our analysis implies potential negative consequences from intensification of the hydrological cycle that has been projected in response to global climate change. Intensification that leads to more extreme rainfall-runoff events (Palmer et al. 2008) will alter the timing and magnitude of flood peaks. In these regions, rivers will be pushed toward the arrhythmic end of the spectrum (Döll and Zhang 2010), potentially reducing deterministic influences on populations and communities (Lewis et al. 2000, Clark 2008), and increasing stochastic influences (Sabo and Post 2008, Rosindell et al. 2012). Ecological responses to altered thermal and precipitation regimes and increased frequency of extreme climatic events have already been observed, including changes in the timing of bird migrations, variable survival of offspring, and mismatches between consumers and prey as well as seed production and pollinators (Helm et al. 2013). Rapid change that alters interannual variation in magnitude and timing of seasonal inundation could shift communities away from species better adapted to exploit predictable flow pulses toward those more tolerant of unpredictable flow pulses that have bet-hedging lifehistory traits such as asynchronous reproduction (Lytle and Poff 2004).

In the near term, effects of altered river hydrology derived from climate change may pale in comparison to more immediate hydrological modifications from dams for hydroelectric power generation, water storage and water diversion for agriculture, industry, and urban areas (Palmer et al. 2008). The rhythmicity framework presented here can be used to consider how river regulation and water extraction may affect the important ecosystem services provided by large river floodplains, and how the management of dams interacts with climate-driven changes to alter runoff characteristics (Palmer et al. 2008; Appendix C: Fig. C2).

Our analysis has implications for the restoration of flood-dependent ecosystems in large rivers where prescribed floods are being used to trigger desired geomorphological and biological responses (Olden et al. 2014). For example, single rare floods, such as those used in the Colorado River (USA) to rebuild sandbars and other in-stream habitats, may not meet other ecological objectives (Cross et al. 2011). A single large flow pulse can effectively move bed materials and create 
backwater habitat; however, flow pulses must occur with sufficient rhythmicity to allow locally adapted organisms to thrive in the face of competition from nonnatives (Cross et al. 2011). Repeated floods that mimic the timing and magnitude of predevelopment conditions (Robinson and Uehlinger 2008) are required for riverfloodplain systems to return to a state that approximates the original distribution of species and their abundances (Poff et al. 2007). Analysis of flow pulse rhythmicity before and after dam construction could assist in prescribing long-term strategies required to restore key functions and structures of river ecosystems.

Relationships between rhythmicity and species diversity, population variation, and riparian primary productivity, coupled with the prior observation that high variation in discharge limits food chain length in rivers (Sabo et al. 2010), lend further support to the idea that hydrological predictability is a key driver of ecological patterns and processes in riverine landscapes. Much like the predictable arrival of spring heralds an oncoming peak in growth and reproduction for biota, so, too, does the rhythmicity of large rivers support productive and diverse life forms that generate ecosystem services for human societies.

\section{ACKNOWLEDGMENTS}

The authors thank the many individuals who assisted with field and laboratory work that generated biological data contained herein, the Global Runoff Data Centre for providing the hydrologic data, and Nigel Stork and two anonymous reviewers for providing valuable comments on earlier versions of the manuscript. Funding for the workshop that led to the manuscript was provided to the Tropical Rivers and Coastal Knowledge (TRaCK) research program by the Australian Government's Commonwealth Environment Research Facilities initiative; the Australian Government's Raising National water Standards Program; Land and Water Australia; the Fisheries Research and Development Corporation; and the Queensland Government's Smart State Innovation Fund. This research was also conducted with the support of funding from the Australian Government's National Environmental Research Program.

\section{Literature Cited}

Aitkenhead, J. A., and W. H. McDowell. 2000. Soil C:N ratio as a predictor of annual riverine DOC flux at local and global scales. Global Biogeochemical Cycles 14:127-138.

Albert, J. S., P. Petry, and R. E. Reis. 2011. Major biogeographic and phylogenetic patterns. Pages 21-57 in J. S. Albert and R. E. Reis, editors. Historical biogeography of Neotropical freshwater fishes. University of California Press, Oakland, California, USA.

Alofs, K. M., E. A. Liverpool, D. C. Taphorn, C. R. Bernard, and H. Lopez-Fernandez. 2014. Mind the (information) gap: the importance of exploration and discovery for assessing conservation priorities for freshwater fish. Diversity and Distributions 20:107-113.

Bechtold, J. S., R. T. Edwards, and R. J. Naiman. 2003. Biotic versus hydrologic control over seasonal nitrate leaching in a floodplain forest. Biogeochemistry 63:53-72.

Burford, M. A., A. J. Cook, C. S. Fellows, S. R. Balcombe, and S. E. Bunn. 2008. Sources of carbon fuelling production in an arid floodplain river. Marine and Freshwater Research 59: 224-234.
Chesson, P., R. L. E. Gebauer, S. Schwinning, N. Huntly, K. Wiegand, M. S. K. Ernest, A. Sher, A. Novoplansky, and J. F. Weltzin. 2004. Resource pulses, species interactions, and diversity maintenance in arid and semi-arid environments. Oecologia 141:236-253.

Chesson, P., and N. Huntly. 1997. The roles of harsh and fluctuating conditions in the dynamics of ecological communities. American Naturalist 150:519-533.

Clark, J. S. 2008. Beyond neutral science. Trends in Ecology and Evolution 24:8-15.

Correia, S. B., and K. O. Winemiller. 2014. Niche partitioning among frugivorous fishes in response to fluctuating resources in the Amazonian floodplain forest. Ecology 95:210-224.

Cross, W. F., C. V. Baxter, K. C. Donner, E. J. Rosi-Marshall, T. A. Kennedy, R. O. Hall, H. A. Wellard Kelly, and R. S. Rogers. 2011. Ecosystem ecology meets adaptive management: food web response to a controlled flood on the Colorado River, Glen Canyon. Ecological Applications 21: 2016-2033.

Döll, P., and J. Zhang. 2010. Impact of climate change on freshwater ecosystems: a global-scale analysis of ecologically relevant river flow alterations. Hydrology and Earth System Science 14:783-799.

Foster, R. G., and L. Kreitzman. 2009. Seasons of life: the biological rhythms that enable living things to thrive and survive. Yale University Press, New Haven, Connecticut, USA.

Gallant, J. C., and T. I. Dowling. 2003. A multiresolution index of valley bottom flatness for mapping depositional areas. Water Resources Research 39:1347-1359.

Gravel, D., F. Guichard, and M. E. Hochberg. 2011. Species coexistence in a variable world. Ecology Letters 14:828-839.

Guégan, J.-F., S. Lek, and T. Oberdorff. 1998. Energy availability and habitat heterogeneity predict global riverine fish diversity. Nature 391:382-384.

Helm, B., R. Ben-Shlomo, M. J. Sheriff, R. A. Hut, R. Foster, B. M. Barnes, and D. Dominoni. 2013. Annual rhythms that underlie phenology: biological time-keeping meets environmental change. Proceedings of the Royal Society B 280: 20130016.

Junk, W. J. 1997. The central Amazon floodplain: ecology of a pulsing system. Springer, Berlin, Germany.

Junk, W. J., P. B. Bayley, and R. E. Sparks. 1989. The flood pulse concept in river-floodplain systems. Canadian Special Publication of Fisheries and Aquatic Sciences 106:110-127.

Kennard, M. J., B. J. Pusey, J. Boyden, C. Leigh, P. Bayliss, and A. Georges. 2010. 5. Compilation of species distribution data sets for use as biodiversity surrogates. Pages $50-58$ in M. J. Kennard, editor. Identifying high conservation value aquatic ecosystems in northern Australia. Final report for the Department of Environment, Water, Heritage and the Arts and the National Water Commission. Tropical Rivers and Coastal Knowledge (TRaCK) Commonwealth Environmental Research Facility, Charles Darwin University, Darwin, Northern Territory 0909 Australia.

Kingsford, R. T., and F. I. Norman. 2002. Australian waterbirds: products of the continent's ecology. Emu 102: 47-69.

Kucharik, C. J., J. A. Foley, C. Delire, V. A. Fisher, M. T. Coe, J. Lenters, C. Young-Molling, N. Ramankutty, J. M. Norman, and S. T. Gower. 2000. Testing the performance of a dynamic global ecosystem model: water balance, carbon balance and vegetation structure. Global Biogeochemical Cycles 14:795-825.

Lake, S., N. Bond, and P. Reich. 2006. Floods down rivers: from damaging to replenishing forces. Advances in Ecological Research 39:41-62.

Lewis, W. M., Jr., S. K. Hamilton, M. A. Lasi, M. Rodriguez, and J. F. Saunders III. 2000. Ecological determinism on the Orinoco floodplain. BioScience 50:681-692. 
Lytle, D. A., and N. L. Poff. 2004. Adaptation to natural flow regimes. Trends in Ecology and Evolution 19:94-100.

Mackey, R. L., and D. J. Currie. 2001. The diversitydisturbance relationship: is it generally strong and peaked? Ecology 82:3479-3492.

Marcarelli, A. M., C. V. Baxter, M. M. Mineau, and R. O. Hall. 2011. Quantity and quality: unifying food web and ecosystem perspectives on the role of resource subsidies in freshwaters. Ecology 92:1215-1225.

Melack, J. M., and L. L. Hess. 2010. Remote sensing of the distribution and extent of wetlands in the Amazon basin. Pages 43-59 in W. J. Junk, F. Piedade, J. Schongart, and P. Parolin, editors. Amazonian floodplain forests: ecophysiology, ecology, biodiversity and sustainable management. Springer, Berlin, Germany.

Miller, A. D., S. H. Roxburgh, and K. Shea. 2011. How frequency and intensity shape diversity-disturbance relationships. Proceedings of the National Academy of Sciences USA 108:5643-5648.

Muneepeerakul, R., E. Bertuzzo, H. J. Lynch, W. F. Fagan, A. Rinaldo, and I. Rodriguez-Iturbe. 2008. Neutral metacommunity models predict fish diversity patterns in MississippiMissouri basin. Nature 453:220-223.

Noe, G. B., C. R. Hupp, and N. B. Rybicki. 2013. Hydrogeomorphology influences soil nitrogen and phosphorus mineralization in floodplain wetlands. Ecosystems 16:75-94.

Olden, J. D., et al. 2014. Are large-scale flow experiments informing the science and management of freshwater ecosystems? Frontiers in Ecology and the Environment 12: 176-185.

Palmer, M. A., C. A. Reidy Liermann C. Nilsson, M. Florke, J. Alcamo, P. S. Lake, and N. Bond. 2008. Climate change and the world's river basins: anticipating management options. Frontiers in Ecology and the Environment 6:81-89.

Parsons, M., C. McLoughlin, K. Kotschy, K. M. Rogers, and M. Rountree. 2005. The effects of extreme floods on the biophysical heterogeneity of river landscapes. Frontiers in Ecology and the Environment 3:487-494.

Poff, N. L. 1992. Why disturbances can be predictable: a perspective on the definition of disturbance in streams. Journal of the North American Benthological Society 11:8692.

Poff, N. L., J. D. Olden, D. M. Merritt, and D. M. Pepin. 2007. Homogenization of regional river dynamics by dams and global biodiversity implications. Proceedings of the National Academy of Sciences USA 104:5732-5737.

Power, M. E., M. S. Parker, and W. E. Dietrich. 2008. Seasonal reassembly of a river food web; floods, droughts, and impacts of fish. Ecological Monographs 78:263-282.
Puckridge, J. T., F. Sheldon, K. F. Walker, and A. J. Boulton. 1998. Flow variability and the ecology of large rivers. Marine and Freshwater Research 49:55-72.

Pusey, B., M. Kennard, D. Burrows, C. Perna, P. Kyne, B. Cook, and J. Hughes. 2011. Freshwater fish. Pages 71-92 in B. J. Pusey, editor. Aquatic biodiversity in northern Australia: patterns, threats and future. Charles Darwin University Press, Darwin, Australia.

Robinson, C. T., and U. Uehlinger. 2008. Experimental floods cause ecosystem regime shift in a regulated river. Ecological Applications 18:511-526.

Robson, B. J., J. Schult, J. Smith, I. Webster, M. Burford, A. Revill, S. Townsend, R. Haese, and D. Holdsworth. 2010. Towards understanding the impacts of land management on productivity in the Daly River. Charles Darwin University, Darwin, Australia.

Rosindell, J., S. P. Hubbell, F. He, L. J. Harmon, and R. S. Etienne. 2012. The case for ecological neutral theory. Trends in Ecology and Evolution 27:203-208.

Sabo, J. L., J. C. Finlay, T. Kennedy, and D. M. Post. 2010. The role of discharge variation in scaling of drainage area and food chain length in rivers. Science 330:965-967.

Sabo, J. L., and D. M. Post. 2008. Quantifying periodic, stochastic, and catastrophic environmental variation. Ecological Monographs 78:19-40.

Shea, K., S. H. Roxburgh, and E. S. J. Rauschert. 2004. Moving from pattern to process: coexistence mechanisms under intermediate disturbance regimes. Ecology Letters 7: 491-508.

Thorp, J. H., M. C. Thoms, and M. D. Delong. 2008. The riverine ecosystem synthesis: toward conceptual cohesiveness in river science. Academic Press, London, UK.

Tockner, K., and J. A. Stanford. 2002. Riverine flood plains: present state and future trends. Environmental Conservation 29:308-320.

Unmack, P. J. 2001. Biogeography of Australian freshwater fishes. Journal of Biogeography 28:1053-1089.

Willig, M. R., D. M. Kaufman, and R. D. Stevens. 2003. Latitudinal gradients of biodiversity: pattern, process, scale, and synthesis. Annual Review of Ecology, Evolution, and Systematics 34:273-309.

Winemiller, K. 2004. Floodplain river food webs: generalizations and implications for fisheries management. Pages 285 309 in R. Welcomme and T. Petr, editors. Proceedings of the Second International Symposium on the Management of Large Rivers for Fisheries. Volume II. Regional Office for Asia and the Pacific, Bangkok, Thailand. RAP Publication 2004/16.

\section{Supplemental Material}

\section{Ecological Archives}

Appendices A-E are available online: http://dx.doi.org/10.1890/14-0991.1.sm 